Recorregut de recerca geològica i mineralògica per la comarca de I'Alt Urgell (amb una petita fillola per la comarca del Solsonès): des de la Vansa a Fornols de Cadí, Cornellana, Tuixent i al Coll del Port

Josep Maria Mata-Perelló

Joaquim Sanz Balagué

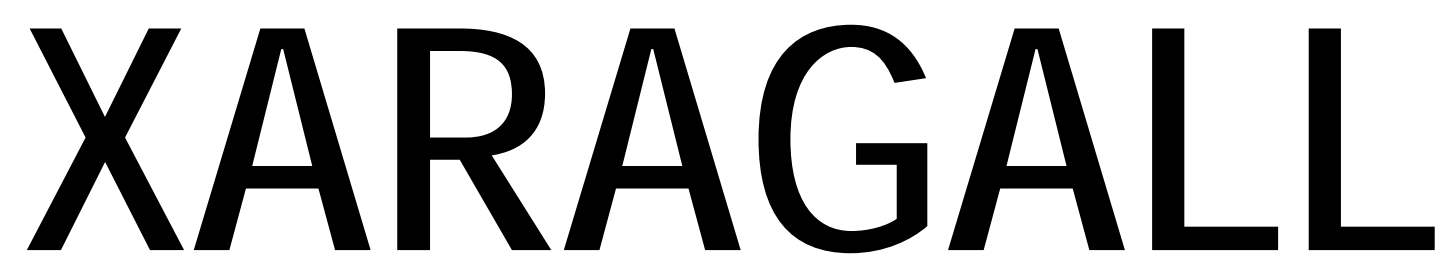

REVISTA DE CIÈNCIES DE LA CATALUNYA CENTRAL

ก. 6

JUNY 2015

Com citar l'article: Mata-Perelló, JM.; Sanz Balaguer, J. Recorregut de recerca geològica i mineralògica per la comarca de l'Alt Urgell (amb una petita fillola per la comarca del Solsonès): des de la Vansa a Fornols de Cadí, Cornellana, Tuixent i al Coll del Port. A: XARAGALL. Revista de Ciències de la Catalunya Central. 2015. (n.6). ISSN 2013-4479 DL: B.21483-2009. DOI 


\title{
RECORREGUT DE RECERCA GEOLÒGICA I MINERALÒGICA PER LA COMARCA DE L'ALT URGELL (AMB UNA PETITA FILLOLA PER LA COMARCA DEL SOLSONĖS): DES DE LA VANSA A FORNOLS DE CADÍ, CORNELLANA, TUIXENT I AL COLL DEL PORT
}

\author{
Josep Maria Mata-Perelló \\ Museu de geologia Valentí Masachs, Escola Politècnica Superior d'Enginyeria de Manresa \\ (EPSEM), Universitat Politècnica de Catalunya · BarcelonaTech (UPC), 08272 Manresa, Spain
}

\section{Joaquim Sanz Balagué}

Departament d'Enginyeria Minera i Recursos Naturals (EMRN), Escola Politècnica Superior d'Enginyeria de Manresa (EPSEM), Universitat Politècnica de Catalunya - BarcelonaTech (UPC), 08272 Manresa, Spain

Paraules clau: Sistema Pirinenc, Materials cenozoics, Patrimoni miner

\section{Resum}

Itinerari realitzat el 13 de juliol de 2014. En aquesta ocasió, el recorregut de l'itinerari discorrerà, en la seva totalitat pel Sistema Pirinenc. I ho farà per dues de les seves sotsunitats.. Així, es circularà per tres de les seves sots unitats: pel Mantell del Pedraforca Inferior, pel Mantell del Pedraforca Superior i pel Mantell del Cadí.

Així, el recorregut s'iniciarà dintre dels afloraments mesozoics (del Triàsic, del Juràssic i del Cretàcic) que formen part del Mantell del Pedraforca Inferior, per on es circularà entre la Vansa i el Coll del Port, tret d'alguns sectors situats prop de Cornellana de Cadí i del mateix Coll de Port. En aquests altres sectors, es circularà pel Mantell del Pedraforca Superior (amb afloraments del Cretàcic) i pel Mantell del Cadí., entre afloraments de materials cenozoics del Paleocè - Eocè.

Per altra banda, tot i que el recorregut de l'itinerari transitarà per la comarca de I'Alt Urgell (entre la Vansa i el Coll de Port), a la darrera aturada es farà una lleu entrada a la comarca veïna del Solsonès, per on finalitzarà el recorregut d'aquest itinerari.

Xaragall.2015 n.6 | Recorregut de recerca geològica i mineralògica per la comarca de l'Alt Urgell (amb una 


\section{Objectius fonamentals}

Es centraran en els aspectes geològics, geomorfològics i mineralògics que apuntarem a continuació, d'acord amb el sentit de la marxa del recorregut:

1. Observació a distancia dels Apilaments Antiformes de la Zona Axial, que veurem des del Coll de Port.

2. Observació de l'estructura de la Zona Sudpirinenca, (i més concretament les seves unitats, com el Mantell del Pedraforca Interior, Mantell del Pedraforca Superior i el Mantell del Cadi). En conjunt, els anirem veient al llarg de tot el recorregut de l'itinerari.

3. Observació dels afloraments del Mantell del Pedraforca Inferior, que nosaltres trobarem pels voltants de Sorribes (la Vansa) fins a la fi del recorregut al Coll de Port, llevat d'alguns indrets. Així, veurem afloraments dels materials mesozoics (del Triàsic, del Juràssic i del Cretàcic).

4. Observació dels afloraments del Mantell del Pedraforca Superior, que nosaltres trobarem pels voltants de Cornellana i de Tuixen. Així, veurem afloraments dels materials mesozoics (del Cretàcic).

5. Observació dels afloraments del Mantell del Cadí, que nosaltres trobarem pels voltants de Cornellana i també al Coll de Port. En aquests trams trobarem afloraments dels materials cenozoics, fonamentalment del Paleocè i de l'Eocè.

6. Observació de les estructures de les unitats geològiques acabades d'esmentar i de les relacions existents entre elles.

7. Reconeixement de diverses mineralitzacions situades al llarg del recorregut, que anem trobant d'acord amb el sentit de la marxa. En aquest itinerari, trobarem

7A) Mineralitzacions bauxitíferes de rebliment de cavitats d'origen kàrstic, situades entre els materials carbonatats mesozoics. Les veurem a Monturgull, al Molí de Fórnols i al Coll de Port

7B) Mineralitzacions evaporítiques guixoses, situades entre els afloraments triàsics del Keuper. Les veurem a Fórnols del Cadí.

8. Reconeixement de les explotacions mineres, antigues i actuals, relacionades amb les mineralitzacions esmentades a l'apartat anterior.

9. Observació dels impactes produïts per les explotacions anteriors, sobre el Medi Natural; així com de les possibles restauracions, si s'han dut a terme.

10. Observació, al llarg del recorregut, dels diferents indrets relacionats amb el Patrimoni Geològic i Miner. 


\section{Antecedents}

En relació a aquest recorregut, no hi ha cap antecedent global. Això si: hi ha diversos antecedents parcials nostres, especialment relacionats amb el Coll de Port. Entre aquests farem esment dels següents: MATA-PERELLÓ (1997a, 1997b, 2005, 2007, 2012 i 2013). Trets d'aquests, no en coneixem cap més.

Pel que toca al coneixement de les estructures geològiques que veurem en aquest itinerari hi ha l'antecedent local de BERASTEGUI et altri (1993); aquest antecedent es relatiu a un treball de I'IGME, relatiu a l'àrea recorreguda. Altres antecedents, de caràcter estructurals, i relatius al conjunt dels Països Catalans, són els següents: RIBA et altri (1976) i GUIMERÀ (1982); així com SGC (1990).

Finalment, i pel que fa a les mineralitzacions que trobarem al llarg del recorregut, ens referirem a: MATA-PERELLÓ (1991). Aquest treball fa referència al conjunt de les mineralitzacions de Catalunya.

Evidentment, totes aquestes referències bibliogràfiques, figuraran degudament relacionades, per ordre alfabètic, dintre de l'apartat dedicat a les REFERÈNCIES BIBLIOGRÀFIQUES.

\section{Recorregut de l'itinerari}

El recorregut d'aquest itinerari començarà a la població alt urgellenca de Sorribes (la Vansa) la capital del municipi de La Vansa, per on farem una primera aturada. Tot seguit, el recorregut es dirigirà cap al poblet agregar de Monturgull, per on es farà una aturada, si s'escau. Després, el recorregut retornarà a Sorribes, per tal d'anar per una carretera local 8no numerada, però asfaltada) cap a Fórnols del Cadi i cap a Cornellana. En aquest trajecte es farà una nova aturada.

Després, el recorregut anirà cap a Tuixén (fent-se una fillola per anar cap el Moli de Fórnols). En aquest trajecte es farà una nova aturada i tot seguit s'arribarà a Tuixén, per on es farà una nova aturada. Seguidament, ara per la carretera local LV - 4012, el recorregut es dirigirà cap el Coll de Port, per on es faran les darreres aturades abans de finalitzar el recorregut de l'itinerari al Solsonès.

\section{Advertiments previs}

Com en altres recorreguts de RECERCA GEOLÒGICA I MINERALÒGICA... si es disposa del temps suficient, poden efectuar-se passant per totes les parades i filloles. En cas contrari, recomanem prescindir de les anomenades PARADES - CONDICIONALS.

També recomanem que es demani informació sobre l'estat dels diferents trams de les pistes forestals, per les quals s' ha de circular, en el recorregut de l'itinerari, per tal d'evitar problemes secundàries. En aquest cas, farem a peu l'accés a la mina de bauxita del Coll de Port; així com a la de Monturgull, si s'escau).

Per altra banda, i a l'igual que en altres recorreguts semblants, recomanem tenir el màxim de cura i de respecte, entorn de la Natura que ens rodeja.

Xaragall.2015 n.6 | Recorregut de recerca geològica i mineralògica per la comarca de l'Alt Urgell (amb una 


\section{Descripció de l'itinerari}

En aquest recorregut hem situat, com ja és habitual en tots els itineraris, una sèrie d'ESTACIONS o de PARADES, que anirem veient a continuació. En cada cas, els hi donarem una denominació que podrà correspondre a algun paratge proper. També indicarem el terme municipal i la comarca on es troba.

Per altra banda, en cadascuna de les parades, indicarem entre parèntesi el número del mapa topogràfic, a escala 1:50.000, on es troba situada la parada considerada. En aquesta ocasió utilitzarem un full de la CME ("Cartografia Militar de España"): concretament 254 (o de Gósol). Així, passarem a continuació, a fer una referència ordenada, de les diferents aturades que composen el recorregut del present itinerari.

\subsection{Parada 1 - CONDICIONAL. ESGLÈSIA DE SORRIBES, (terme municipal de la Vansa - Fórnols, comarca de I’Alt Urgell). (Full 254).}

El recorregut d'aquest itinerari, el començarem en aquest indret, al poble de Sorribes, que n'és la capital del municipi de la Vansa - Fórnols. De fet és pròpiament la Vansa. Així, l'inici el farem a la seva església parroquial.

En aquest indret, estem situats plenament dintre del Sistema Pirinenc i més concretament dintre del Mantell Inferior del Pedraforca. Així, es fan palesos per arreu els afloraments dels materials mesozoics, eminentment carbonatats. Aquests materials són Cretàcics. També es veuen afloraments dels nivells del Triàsic Superior, del Keuper.

Per altra banda, des d'aquest indret es pot gaudir de la observació del riu de la Vansa, el qual es afluent del riu Segre. Cal considerar que aquest riu s' ha desbordant varies vegades durant els darrers anys.

\subsection{Parada 2 - CONDICIONAL. MONTURGULL. (Monturgull, actualment es del terme municipal de La Vansa i Fórnols, comarca de l’Alt Urgell). (Full 254).}

Després de realitzar la parada anterior, cal fer una fillola, des de Sorribes, per tal d'anar cap el seu agregat: el poblet de Monturgull. Des d'aquí, caldrà continuar a peu, travessant el riu de la Vansa i ascendint uns 20 minuts, cap a Padrinàs. Així, s'arribarà a l'indret de l'aturada. Haurem recorregut uns $3 \mathrm{Km}$ des de la parada anterior, poc més d'un d'ells fet a peu.

En aquest recorregut, no hem abandonat el Mantell Inferior del Pedraforca, per on estem situats des de l'inici del recorregut. Així, ara per aquest indret es fan palesos els afloraments de materials carbonatats de la Formació Bonansa, del Juràssic.

En aquest indret, al mateix costat del camí, es troba un interesant rebliment de cavitats càrstiques, amb BAUXITES, i que també es troba entre els materials calcaris de la Formació Bonansa, del Juràssic, i dintre del Mantell Inferior del Pedraforca. 


\subsection{Parada 3. GUIXERA DE FÓRNOLS (Fórnols del Cadí, terme municipal de La Vansa i Fórnols, comarca de I’Alt Urgell). (Full 254).}

Després de fer la parada anterior, cal retornar al poble de Sorribes, per tal de continuar ara cap el Nord, per la carretera que condueix a la Seu d'Urgell. En arribar al poble de Fórnols de Cadí, ens caldrà fer una fillola, baixant pel camí (transitable) que condueix cap al Molí de Fórnols. A uns $2 \mathrm{Km}$ de poble abans esmentat, farem una nova aturada. Així, des de l'anterior, haurem efectuat un recorregut total d'uns $10 \mathrm{Km}$, set d'ells des de Sorribes.

En aquest recorregut, hem continuat trobant afloraments dels materials mesozoics que formen part del Mantell del Pedraforca Inferior, per on estem ara situats. Així, haurem trobat, fonamentalment nivells de calcaries i de calcolutites cretàciques. També, com ara, hem trobat afloraments dels nivells argilosos y guixosos del Triàsic Superior, del Keuper. Aquests són els materials que apareixen a l'indret de la present aturada. Es tracta d'un aflorament dels materials guixosos i argilosos del Keuper (Triàsic Superior), que pertanyen a la Formació Pont de Suert, i s'inclouen entre el Mantell Inferior del Pedraforca. Entre aquests materials predominen en aquest indret els primers.

Cal fer esment de la presència dels següents minerals, entre els nivells de guixos: ANHIDRITA, GUIX (naturalment, és el més abundant), i HEMIHEDRITA. Aquests materials van ésser explotats per al benefici dels guixos, però sense gaire èxit.

\subsection{Parada 4. CARRETERA A CORNELLANA (Fórnols del Cadí, actualment del terme municipal de la Vansa - Fórnols del Cadí, comarca de I’Alt Urgell). (Full 254).}

Des de l'indret anterior, caldrà tornar a Fórnols del Cadí. Després de sobrepassar aquest poble, poc abans de trobar el trencall de Cornellana, caldrà fer la present parada, sobre la mateixa carretera. Així, des de la parada anterior, haurem fet un recorregut d'uns $3 \mathrm{Km}$, aproximadament.

Després de fer l'aturada anterior. Hem continuat trobant afloraments dels materials esmentats a l'aturada anterior, els nivells carbonatats del Mantell Inferior del Pedraforca. Tot i així, prop de l'indret de l'aturada, s'hauran fet palesos també els nivells cenozoics del Mantell del Cadí, especialment a llevant d'on ara som.

Tot i així, des d'aquest indret, es fa ben palès l'encavalcament dels materials Juràssics i Cretàcics del Mantell Inferior del Pedraforca (que formen el Santaló), sobre els materials terciaris eocènics del Mantell del Cadí. Uns i altres, presenten un clar cabussament cap al Sud. (fotografia 1). 


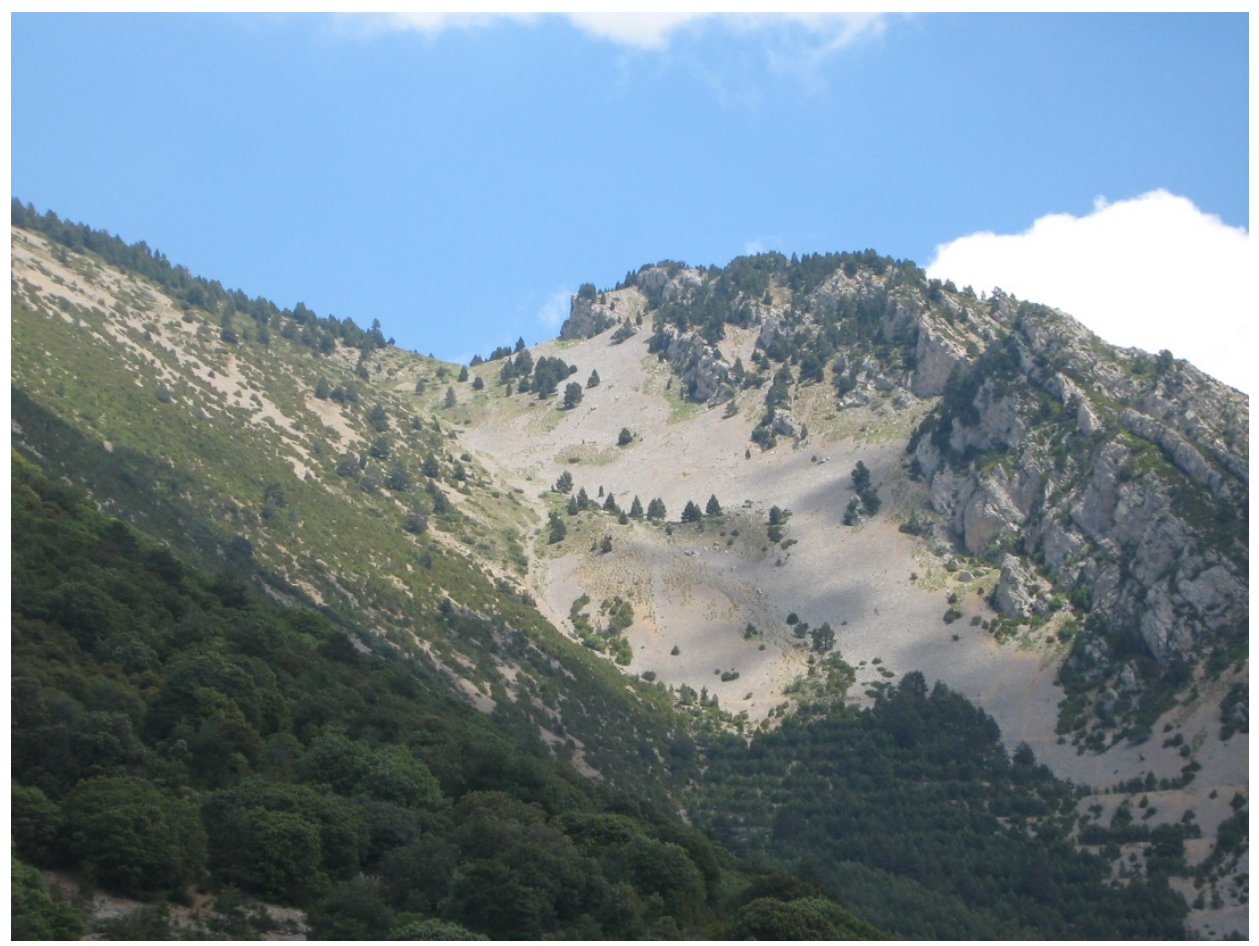

Fotografia 1. L’encavalcament del Mantell del Pedraforca Superior (dreta) sobre el Mantell del Cadí (esquerra). El primer amb nivells carbonatats cretàcic. El segon amb calcàries cenozoiques. Cornellana

Cal dir que aquests materials carbonatats del Cretàcic Inferior, del Mantell del Pedraforca Superior, també encavalquen als materials mesozoics cretàcics del Mantell del Pedraforca Inferior. Finalment, cal dir que tots encavalcaments s' han produïts sobre làmines del Keuper, del Triàsic Superior, les quals es fan evidents per arreu.

\subsection{Parada 5. CRUÏLLA A JOSA DEL CADÍ, (antic terme municipal de Tuixén, i actualment del terme municipal de Tuixén - Josa del Cadí, comarca de l’Alt Urgell). (Full 254).}

Des de la parada anterior, caldrà continuar cap al proper poble de Cornellana, i després cap a Tuixén. Abans d'arribar-hi, i de passar el Riu de Josa, es troba l'indret de la parada. Així, haurem efectuat un recorregut aproximat d'uns $7-8 \mathrm{Km}$.

En el recorregut, des de la parada anterior, es van tallant els materials terciaris de l'Eocè, que formen part del Mantell del Cadí, que hem trobat a l'indret de la parada abans efectuada. Després en sobrepassar el primer poble $\mathrm{i}$ en arribar al Torrent de Cornellana, es talla l'encavalcament assenyalat a la parada anterior, i es penetra al Mantell Superior del Pedraforca (que aquí constitueix el Santaló). En el trajecte fins a la vall del Riu Josa, es van tallant els nivells carbonatats del Juràssic i del Cretàcic Inferior, que formen part del darrer mantell esmentat.

A l'indret de la parada, situat als peus de Tuixén, i al costat del Riu Josa, al trencall del camí que es dirigeix cap a Josa de Cadí i Gósol, es fa palès un encavalcament intern, entre els mateixos materials del Mantell Superior del Pedraforca.

Xaragall.2015 n.6 | Recorregut de recerca geològica i mineralògica per la comarca de l’Alt Urgell (amb una 
Així, el sector del Moixó, situat al SE de Tuixén (i al mateix costat del poble), que hem seguit des de la parada anterior, encavalca al sector del Santaló (situat al NW de Tuixén). I entremig dels dos, el Riu de Josa, de direcció en aquest indret, de NE-SW, va seguint el pla d'encavalcament, per on afloren molt minsament els nivells tous del Keuper, constituïts per nivells de guixos i d'argiles.

\subsection{Parada 6 - CONDICIONAL. MOLÍ DE FÓRNOLS (Fórnols, pertanys a l'actual terme municipal de La Vansa i Fórnols, comarca de l'Alt Urgell). (Full 254).}

Després de realitzar la parada anterior, cal fer una fillola, pel trencall que se'n va cap a de Sorribes de La Vansa, per on caldrà continuar. En menys de $1,5 \mathrm{Km}$ des del trencall, s'arribarà al Molí de Fórnols. Des d'aquest indret, es pot agafar un camí que s'adreça al Càmping, i que travessa el riu de La Vansa, per enlairar-se després cap a la Costa de la Vila, situada al Sud del Molí. A poca distància del pont (a $1 \mathrm{Km}$, aproximadament), podem fer la present aturada, aproximadament a uns $3 \mathrm{Km}$ de l'anteriorment realitzada.

Després de fer la parada anterior, hem deixat els materials carbonatats del Mantell Superior del Pedraforca i l'itinerari ha discorregut entre els materials del Keuper (formats per nivells de guixos i de lutites). Poc després hem entrat en el Mantell Inferior del Pedraforca, el qual es troba encavalcat pel Mantell Superior del Pedraforca (que hem vist abans). Ara, hem començat a trobar afloraments carbonatats del Juràssic. Tanmateix es troben també afloraments carbonatats que pertanyen al Cretàcic Inferior.

En aquest indret es troben uns afloraments de nivells carbonatats mesozoics, sobre les quals hi ha unes mineralitzacions de rebliments de cavitats d'origen kàrstic, amb minerals d'alumini. Aquestes cavitats es troben als nivells calcaris mesozoics juràssics, de la Formació Bonansa, que s'inclouen en aquest indret entre els afloraments del Mantell Inferior del Pedraforca.

Pel que fa a la mineralització de rebliment de cavitats d'origen Kàrtstic, cal dir que presenta una composició Al-Fe. Entre els minerals d'alumini presents, que es troben constituint BAUXITES, cal fer esment dels següents minerals: BOEHMITA, DIASPOR, GIBBSITA i CAOLINITA. També es troba present un mineraloid, I'ALUMOGEL. Per d'altra banda, són igualment presents els minerals de ferro, especialment I'HEMATITES, que comunica el seu color rogenc a les bauxites. També hi és present un altre mineral de ferro, la GOETHITA (en forma de limonita). Finalment, també es pot parlar de la presència minoritària de CALCITA.

Per acabar, cal dir que aquestes mineralitzacions van ésser recercades durant els anys 50-60. Tot i així no es van arribar mai a explotar.

\subsection{Parada 7. CARRETERA A JOSA DEL CADÍ, TORRENT DE COLLELL, (Josa del Cadí, terme municipal de Josa i Tuixén, comarca de l’Alt Urgell). (Full 254).}

Després de realitzar l'aturada anterior, cal retornar al pont sobre el riu Josa, per on hem fet I'aturada 5. A partir d'aquí, ens caldrà iniciar una segona fillola, per tal d'apropar-nos cap al poble de Josa del Cadí, sobrepassant-lo, per tal d'arribar al pont de la carretera sobre el Torrent del Collell. Aquí podem fer una nova aturada, aproximadament a uns $4 \mathrm{Km}$ de Josa i ans 8 de l'inici de la fillola.

En aquest recorregut, hem anat circulant pels voltants de l'encavalcament del Mantell del Pedraforca Superior (que da a la dreta, al Sud del recorregut) i els materials cenozoics del Mantell del Cadí, que es fan palesos a l'esquerra (al Nord). Tot i així, en arribar a Josa, s'han fet palesos els materials del Juràssic Superior - Cretàcic Inferior, que corresponen al Mantell

Xaragall.2015 n.6 | Recorregut de recerca geològica i mineralògica per la comarca de l'Alt Urgell (amb una 
del Pedraforca Inferior. Aquest, al Sud d'on ara som, es troba encavalcat per l'altre mantell del Pedraforca.

Per altra banda, ara, a l'indret de l'aturada, es poden veure els afloraments dels materials juràssics i cretàcics del Mantell Inferior del Pedraforca, on estem ara situats. Aquests materials també els trobem a ponent d'on ara som, al Cadinell (situat prop de Josa del Cadí, al Nord del poble). Per d'altra banda, també es poden veure els materials carbonatats eocènics del Mantell del Cadí, al Nord d'on ara som. Tanmateix, des d'aquest indret, es pot veure (o al menys, intuir) com els materials cretàcics del Mantell del Pedraforca Inferior encavalquen als cenozoics del Mantell del Cadí. (fotografia 2).

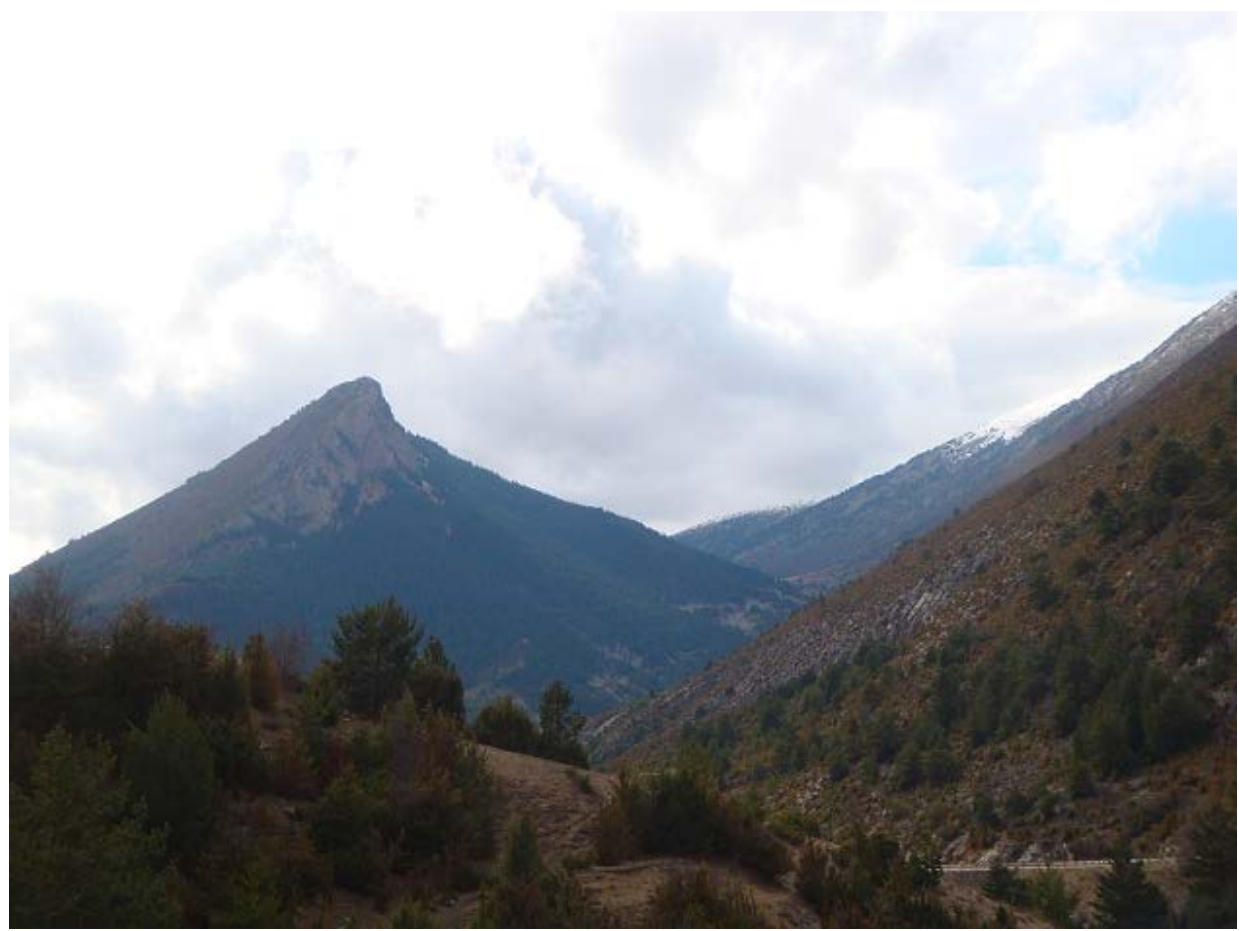

Fotografia 2. El Cadinell, prop de Josa de Cadí, amb afloraments de calcàries juràssiques i cretàciques, del Mantell Inferior del Pedraforca.

A la dreta es veuen els terrenys carbonats eocènics del Cadí (Mantell del Cadl), encavalcats pels anteriors

Al sud d'on ara som, es fa palès l'encavalcament d'aquests materials del Mantell del Pedraforca Inferior, per part dels materials carbonatats del Mantell del Pedraforca Superior, que constitueixen els relleus del Millet i de la Costa Freda. (esquema 1).

Xaragall.2015 n.6 | Recorregut de recerca geològica i mineralògica per la comarca de l'Alt Urgell (amb una 


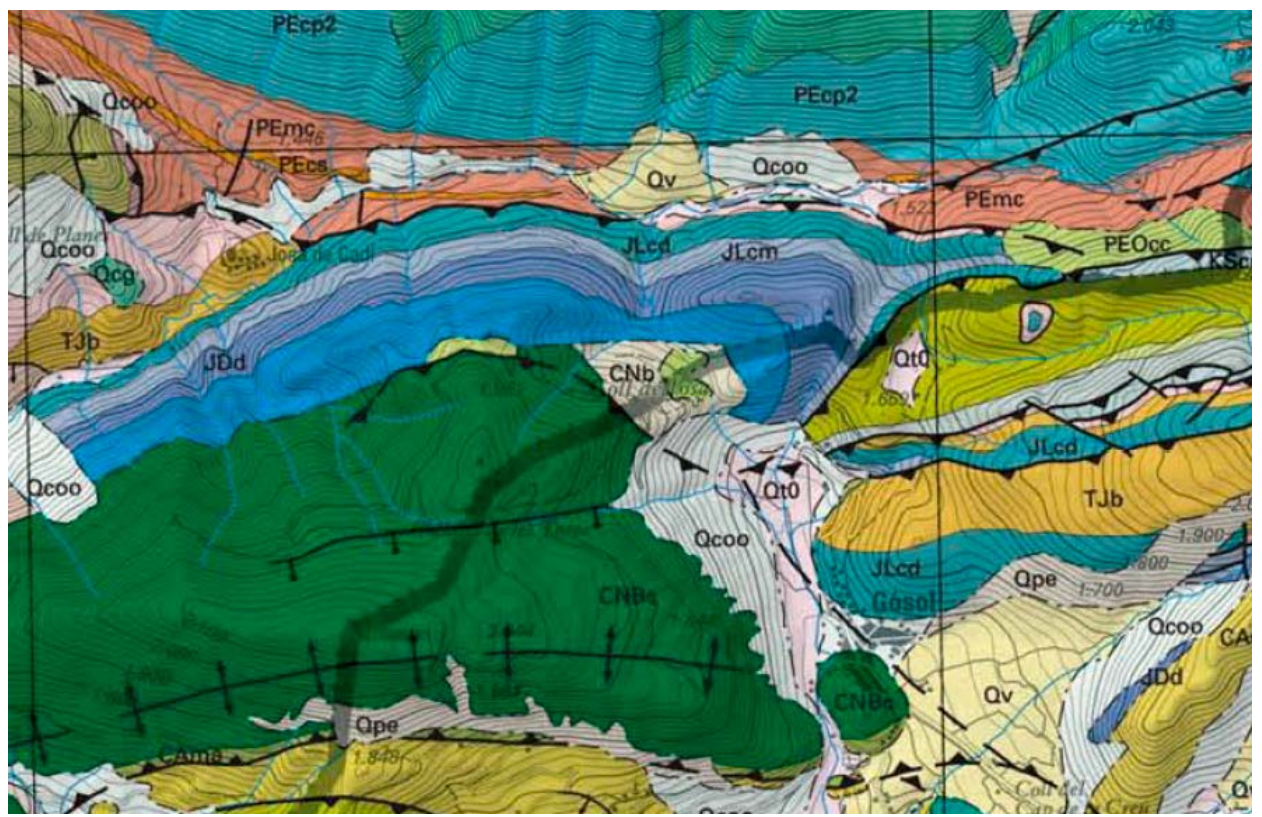

Esquema 1. Es pot veure l'encavalcament del Mantell del Pedraforca Superior, sobre el Mantell del Pedraforca Inferior. I d'aquest sobre el Mantell del Cadí. Tret del Mapa Geològic de l'Alt Urgell, ICGC.

\subsection{Parada 8. RIU DE LA MOLA (de l’antic terme de Tuixén, actualment del terme municipal de Tuixén i Josa del Cadí, comarca de I’Alt Urgell). (Full 254).}

Després de realitzar l'aturada anterior, cal retornar cap a les immediacions de l'indret on hem iniciat la fillola. En arribar-hi, cal continuar per aquesta carretera cap el poble de Tuixén. Abans d'arribar-hi, trobarem la carretera local LV - 4012 (procedent de la Seu d'Urgell i que es dirigeix cap a Tuixén). Després d'arriar a aquesta població, cal continuar encara un parell de quilòmetres per tal d'arribar al Riu de la Mola. Aquí coincidint amb una corba de la carretera, caldrà fer la present parada. Així, des de l'anterior, haurem recorregut uns 10 Km.

En aquest trajecte, haurem estat circulant per la zona d'encavalcaments esmentada a la parada anterior. Així, en arribar a Tuixén, haurem vist els afloraments dels materials cretàcics del Mantell del Pedraforca Superior. Poc després, en arribar a l'indret de la present aturada.

Aquí, ara, trobarem els afloraments dels materials carbonatats del Juràssic i del Cretàcic, els formen part del Mantell Inferior del Pedraforca, es quals es veuen encavalcats pels del Mantell Superior del Pedraforca, situat al Nord, tot constituint els relleus del Moix.

\subsection{Parada 9. COLL DE PORT, (termes municipals de Josa i Tuixén i la Coma, comarques de l'Alt Urgell i del Solsonès). (Full 254).}

Després de realitzar l'aturada anterior, cal continuar per la carretera local LV - 4012, pujant cap el Coll de Port. En arribar-hi, haurem passat de la comarca de l'Alt Urgell a la del Solsonès. En aquest indret farem una nova aturada, a uns 7’5 Km de la parada anterior.

En aquest recorregut, pujant cap el Coll de Port, hem anat trobant afloraments del Mantell del Pedraforca Inferior. Això es farà força evident en arribar a les corbes del Roc de I’Escloper, la

Xaragall.2015 n.6 | Recorregut de recerca geològica i mineralògica per la comarca de l'Alt Urgell (amb una petita fillola per la comarca del Solsonès): des de la Vansa a Fornols de Cadí, Cornellana, Tuixent i al Coll del 
ruta s'introdueix ja dintre d'aquest, que aquí es troba representat per nivells calcaris, gresosos i calcolutítics del Cretàcic Superior.

Així, aquests materials mesozoics del Mantell Inferior del Pedraforca, els anirem trobant fins a l'indret de la parada. Tot i així, en aquest indret estem a la zona de contacte entre aquest darrer mantell (que aquí constitueix la Serra del Verd, especialment cap a llevant) i el Mantell de Cadí (que aquí constitueix la Serra del Port de Compte). Aquest contacte, es realitza per encavalcament del primer sobre el segon, com hem abans

Després, en arribar a l'indret de l'aturada, es podrà gaudir d'un immillorable lloc d'observació. Així, d'aquest indret, mirant cap al Nord, es pot gaudir d'una bona observació dels dos mantells acabats d'esmentar: entre el Mantell del Pedraforca Inferior Fonamentalment amb els relleus dels voltants de Tuixén i el Cadinell) i el Mantell del Cadí (amb la Serra del Cadí). Molt més cap al Nord, i en dies extraordinàriament clars, es pot gaudir d'una bona visió dels relleus de la zona axial (dels anomenats Apilaments Antiformes de la Zona Axial; això sí, molt llunyans. (fotograifa 3)

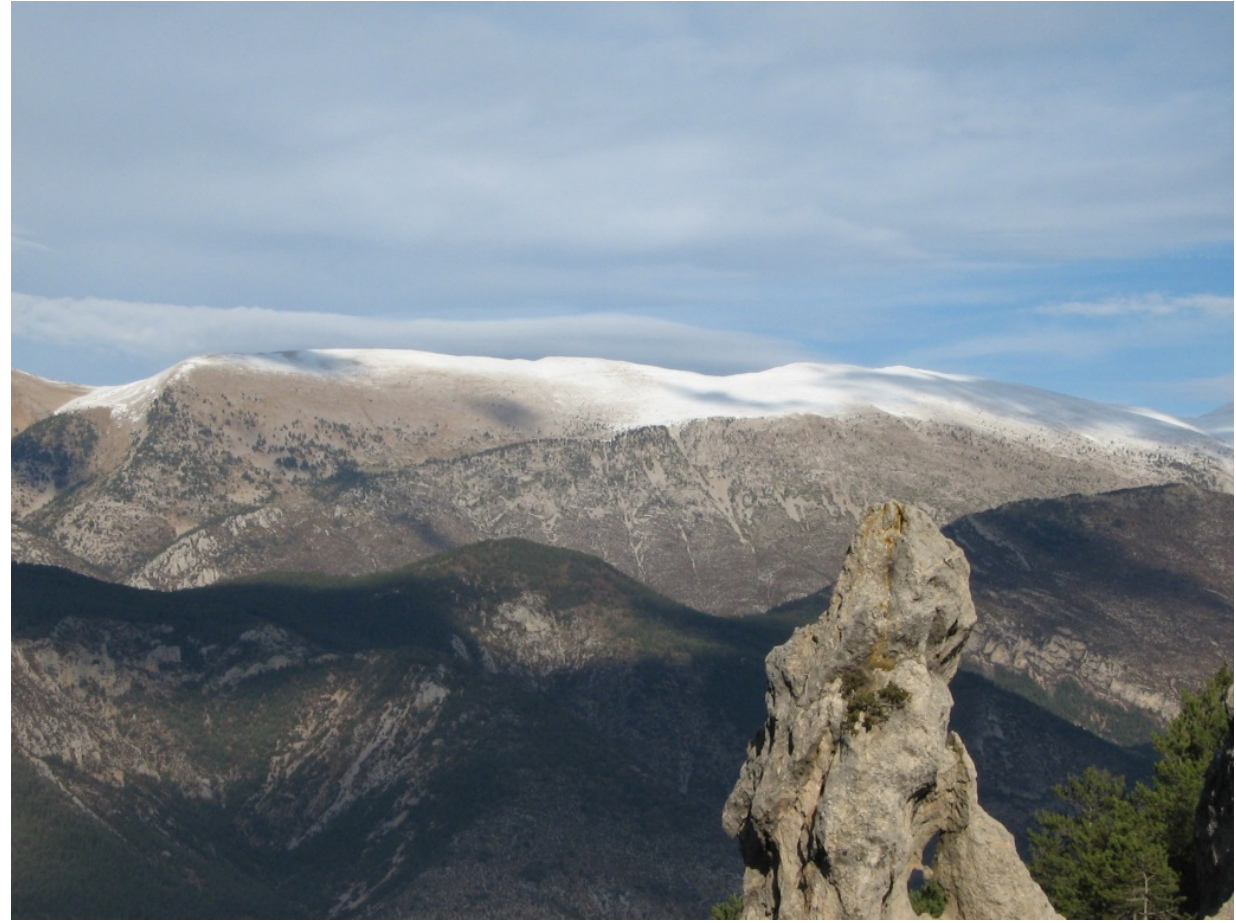

Fotografia 3. En primeríssim terme: les calcàries juràssiques i cretàciques de la Serra del Verd (Mantell del Pedraforca Inferior).

En segon i tercer terme: els relleus carbonatats cretàcics dels voltants de Tuixén i el Cadinell (Mantell del Pedraforca Inferior)

En darrer terme: les calcàries cenozoiques del la Serra del Cadí (Mantell del Cadí)

Tot això, des del Coll de Port 


\subsection{Parada 10. MINA DE BAUXITA DEL COLL DE PORT (termes municipals de Tuixén i de la Coma i la Pedra, comarques de l'Alt Urgell i del Solsonès, respectivament). (Full 254).}

Després de la parada anterior, cal fer un brevíssim recorregut a peu. Així cal agafar un caminat que surt del Port cap al Sud. Aquest camí (situat a l'esquerra de la carretera) és ascendent. En arribar al pla, cal agafar un corriolet que va cap a la carena. Al costat del caminet es troba una antiga explotació, on farem aquesta darrera aturada. Així, haurem recorregut uns $100 \mathrm{~m}$ des del coll.

En aquest breu recorregut, hem anat trobant en tot moment uns afloraments de calcaries mesozoiques del Juràssic. Aquestes calcàries pertanyen al Mantell Inferior del Pedraforca, on estem situats.

Dintre d'elles hi ha mineralitzacions de rebliment de cavitats d'origen kàrstic. Es tracta d'una mineralització d’ $\mathrm{Al}-\mathrm{Fe}$, des del punt de mira del seu quimisme.

Entre els minerals d'alumini presents, cal fer esment dels següents: BOEHMITA (com a bauxita), DIASPOR (bauxita), HIDRARGIRITA (bauxita) i CAOLINITA. També hi ha presència d'ALOMOGEL.

I entre els minerals de ferro, cal esmentar la presència de GOETHITA (en forma de limonita) $i$ HEMATITES (molt abundant, és el mineral que comunica el seu color roig a la bauxita, i a tot el conjunt). Finalment, cal dir que en aquest indret es va realitzar una cata de reconeixement, però els resultats no van ésser gaire positius.

Sobre aquestes mineralitzacions es va realitza una cata de reconeixement.. Els resultats no van ésser gens positius. (fotografia 4).

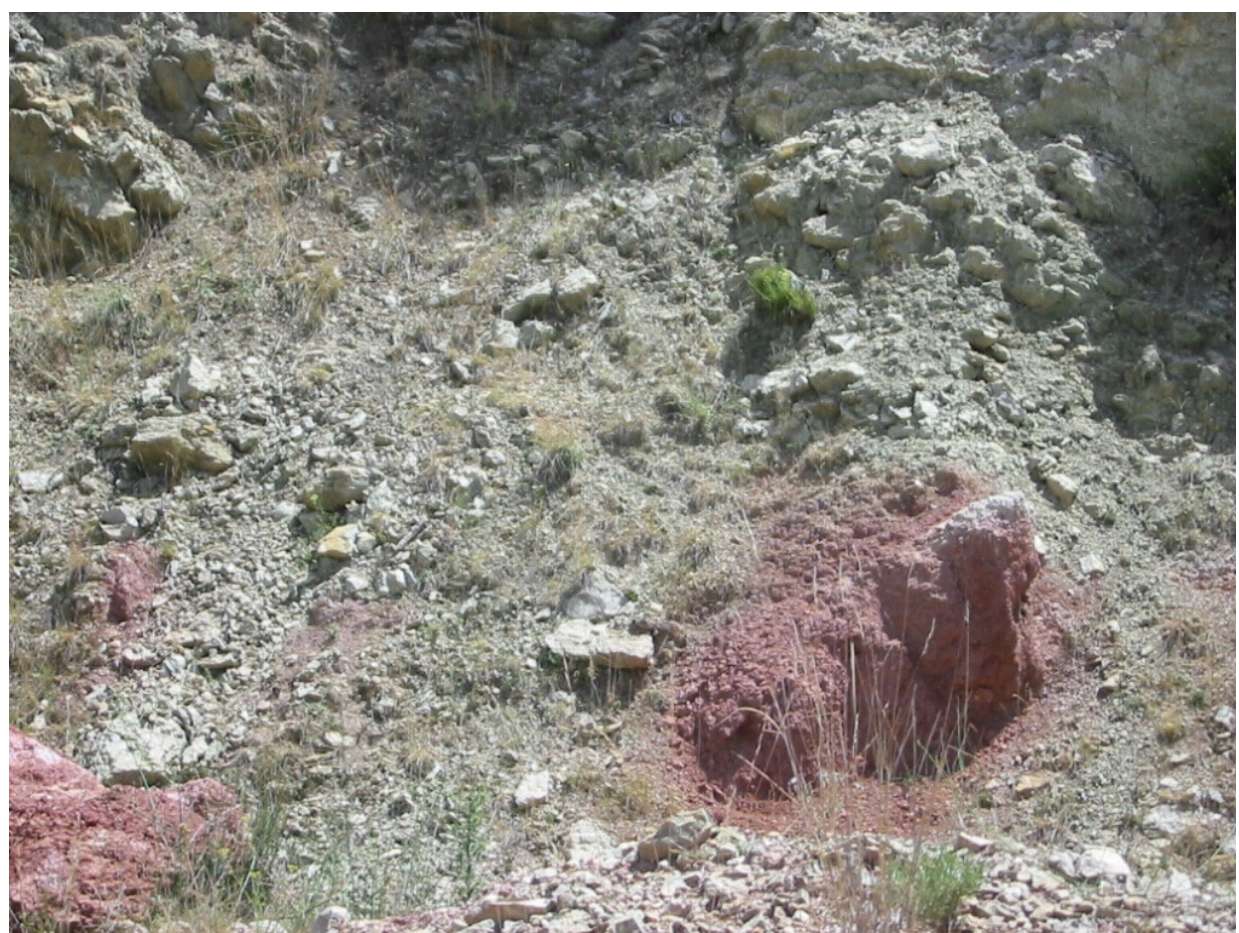

Fotografia 4. Aspecte d'una de les bossades de bauxita

Xaragall.2015 n.6 | Recorregut de recerca geològica i mineralògica per la comarca de l'Alt Urgell (amb una petita fillola per la comarca del Solsonès): des de la Vansa a Fornols de Cadí, Cornellana, Tuixent i al Coll del 
En aquest indret finalitza el recorregut de l'itinerari

\section{Bibliografia}

BERASTEGUI, X. et altri ( 1993).- Tall geològic del Pirineu central. Servei Geològic de Catalunya, Institut Cartogràfic de Catalunya. Col·lecció 1:200.000. Barcelona.

GUIMERÀ, J. et altri (1992).- Geologia (II), Història Natural dels Països Catalans, Vol. 2, 547 pag. Enciclopèdia Catalana, S.A. Barcelona.

MATA-PERELLÓ, J.M. (1991).- Els Minerals de Catalunya. Arxius de la Secció de Ciències, t. XCIII, 442 pag. Institut d’Estudis Catalans. Barcelona.

MATA-PERELLÓ,J.M. (1997a).- Itinerari geològico - mineralògic per I’Alt Urgell: de Tuixén a Tres Ponts. Inèdit, 8 pag. Manresa.

MATA-PERELLÓ,J.M. (1997b).- Recerca geològica i mineralògica per les comarques del Solsonès i de l'Alt Urgell: des de Sant Llorenç de Morunys al Coll del Port i a Tuixén. Inèdit, 11 pag. Manresa.

MATA-PERELLÓ,J.M. (2005).- Recorregut de recerca geològica i mineralògica per les comarques del Solsonès i de I'Alt Urgell: des de Solsona a Alinyà i a la Vansa. Inèdit, 10 pag. Manresa.

MATA-PERELLÓ,J.M. (2007).- Recorregut de recerca geològica i mineralògica per les comarques de la Cerdanya, Alt Urgell i Solsonès: des de Martinet i Arenys de Bar a Toloriu, Tuixén i al Coll de Port. Inèdit, 10 pag. Manresa.

MATA-PERELLÓ,J.M. (2012).- Recorregut de recerca geològica, mineralògica i minera per les comarques del Berguedà, Alt Urgell i Solsonès: des de Vallcebre a Gósol, Josa del Cadí, Tuixén i al Port de Compte. Inèdit, 8 pag. Manresa.

MATA-PERELLÓ,J.M. (2013).- Recorregut de recerca geològica i geoambiental per la comarca del Solsonès: des de Solsona a la Llosa del Cavall, a Sant Llorenç de Morunys i al Port del Compte. Inèdit, 14 pag. Manresa.

MATA-PERELLÓ, J.M. i SANZ BALAGUÉ, J. (1993).- Guia de Identificación de Minerales, adaptada fundamentalmente a la Península Ibérica. Parcir, Edicions Selectes. 205 pàgines. Manresa.

RIBA ARDERIU, O. Et altri. (1976).- Geografia Física dels Països Catalans. Edit Ketres, 254 pàgines. Barcelona.

SGC (1990).- Mapa Geològic de Catalunya a escala 1:250.000, Servei Geològic de Catalunya (Inst. Cartograf. de Catalunya). Barcelona. 